\section{Twists, Turns \& Entanglement - Complexity and the tricky challenges of sport for the athlete and practitioner}

\author{
Philip Glasgow, ${ }^{1,2}$ Stephen Mutch ${ }^{3,4}$
}

Complex decision making is a central pillar of working in performance sport. Are players available for training or competition? What is the optimal training content and progression for an athlete? What is the best intervention for the athlete to resolve an injury while supporting performance? These and many other questions are part of any normal day working in sports medicine. This ACPSEM issue of BJSM (figure 1) highlights the complex and changing environment in which practitioners work and encourages us to avoid a simple linear approach but rather seek to synthesise a wide range of factors to help us make better judgements.

\section{THE ENTANGLED WEB OF RISK FACTORS, CONSTRAINTS \& INJURY}

Over recent years, complex systems theory has improved our understanding of the interactions between various factors and sports injury. In a fascinating review, Mr Rafel Pol and colleagues from Barcelona (see page 1214) discuss how dynamic systems may help us to shift our focus from risk factors to a constraints approach that considers personal, environmental and task-related factors. They highlight that training workloads should be prescribed not only in response to seasonal demands but also to personal and environmental factors that may change in very short timescales. Assessing the role of season demands across 15 different countries, Prof Jan Ekstrand and colleagues (see page 1231) report that the absence of a winter break in English football was associated a higher incidence of severe injuries than other teams who had their scheduled break.

\footnotetext{
${ }^{1}$ School of Sport, Ulster University, Newtownabbey, UK Irish Rugby Football Union, Dublin, Ireland ${ }^{3}$ SPACE Clinics, Edinburgh, UK

${ }^{4}$ Scottish Rugby, Edinburgh, UK
}

Correspondence to Professor Philip Glasgow, School of Sport, Ulster University, Newtownabbey BT37 0QB, UK; philglasgow@hotmail.com

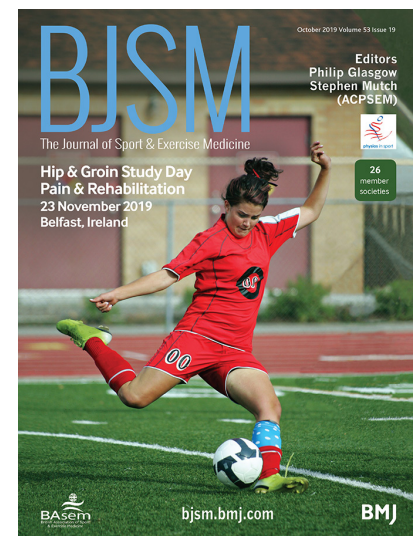

Figure 1 The ACPSEM (@Physiosinsport) Autumn Study Day for 2019 focuses on hip and groin pain in sport. Belfast, November $23^{\text {rd }}$, 2019.

\section{MONITORING THE COMPLEX INDIVIDUAL - BY THE INDIVIDUAL? PERFORMANCE BENEFITS TO BE GAINED?}

Monitoring of individual factors is discussed in an editorial by Dr Johann Windt et al (see page 1202). Although we live in an era of big data where many different training variables are measured and interpreted, the authors highlight the importance of self-reported measures to manage training load. They suggest regular athlete monitoring that leaves room for integrated evaluative judgement has the potential to support a more nuanced clinical approach and effectively support performance. A similar conclusion in radiology is posited by radiologists Drs Parker and Forster (see page 1201) who suggest artificial intelligence may assist clinicians in detecting abnormalities allowing them to make better clinical decisions.

Multi-factorial, complex interactions also seem to apply to longer-term health benefits. In a population cohort-based study of over 1.2 million men, Dr Hanna Henriksson et al (see page 1221) report that being strong was associated with lower rates of disability pension whereas low muscular strength was strongly associated with psychiatric and nervous system disability 30 years later. The specific interaction between strength and psychological factors is not clear but reinforces the need for a biopsychosocial approach to patient care.
Biopsychosocial management of whiplash injuries was shown to out-perform exercise only interventions in an original article by Prof Michele Sterling et al (see page 1240). Stress-inoculation training in addition to guideline based therapy provided significantly better results highlighting again the importance of taking into account multiple factors in the management of patients.

\section{TWISTING \& TURNING - AND MUCH, MUCH MORE FOR THE HIP IN KICKING SPORTS!}

The ACPSEM (@Physiosinsport) Autumn Study Day for 2019 focusses on the management of hip and groin pain, particularly for athletes in kicking sports, no strangers to twists and turns themselves on the field. (figure 1) The complex interaction of risk factors including sex differences, biomechanics, diagnostic criteria and return to sport testing, strategies and pain management of the kicking athlete will all be explored in a manner that permits practical delivery of evidence-informed research.

Experts in the field have been invited as key speakers with well-established academic and applied sporting backgrounds. Speakers have been charged with delivering on the practical application of current research and how to apply them to optimise athlete outcomes.

Adopting an interactive workshop-based approach, this event will help attendees make better informed decisions. The event takes place at Riddel Hall, Queen's University in beautiful Belfast on Saturday 23rd November. As an introductory bonus, there is a Bolt-On Friday evening event outlining the principles of diagnosis and management-ideal as an adjunct to the Saturday! We look forward to seeing you there and remember to follow us on Twitter@ PhysiosInSport.

Funding The authors have not declared a specific grant for this research from any funding agency in the public, commercial or not-for-profit sectors.

Competing interests None declared.

Patient consent for publication Not required.

Provenance and peer review Commissioned; internally peer reviewed.

(C) Author(s) (or their employer(s)) 2019. No commercial re-use. See rights and permissions. Published by BMJ.

\section{Check for updates}

To cite Glasgow P, Mutch S. Br J Sports Med 2019;53:1197.

\section{Accepted 9 September 2019}

Br J Sports Med 2019;53:1197

doi:10.1136/bjsports-2019-101518 